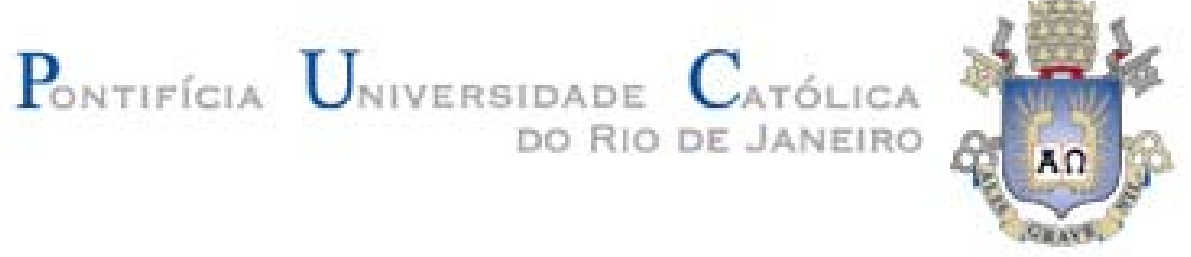

Viviane de Medeiros Calaça Gomes

Influência de Avaliações Online Negativas na Atitude e na Intenção de Compra

Dissertação de Mestrado Dissertação apresentada ao Programa de Pósgraduação em Administração de Empresas da PUCRio como requisito parcial para obtenção do título de Mestre em Administração de Empresas.

Orientador: Prof. Luis Fernando Hor-Meyll Alvares

Rio de Janeiro

Abril de 2012 
Viviane de Medeiros Calaça Gomes

\title{
Influência de Avaliações Online Negativas na Atitude e na Intenção de Compra
}

\begin{abstract}
Dissertação apresentada como requisito parcial para obtenção do grau de Mestre pelo Programa de Pósgraduação em Administração de Empresas da PUC-Rio. Aprovada pela Comissão Examinadora abaixo assinada.
\end{abstract}

Prof. Luis Fernando Hor-Meyll Alvares Orientador

Departamento de Administração - PUC-Rio

Prof. Jorge Brantes Ferreira Departamento de Administração - PUC-Rio

Prof. Eduardo André Teixeira Ayrosa FGV

Profa . Mônica Herz Vice-Decana de Pós-Graduação do CCS 
Todos os direitos reservados. É proibida a reprodução total ou parcial do trabalho sem autorização da autora, do orientador e da universidade.

\section{Viviane de Medeiros Calaça Gomes}

Graduou-se em Engenharia Eletrônica e de Computação na UFRJ (Universidade Federal do Rio de Janeiro) em 2004.

Ficha catalográfica

Gomes, Viviane de Medeiros Calaça

Qualidade e Quantidade das Avaliações Online Negativas: Influência na Atitude e na Intenção de Compra de Consumidores Comprometidos com a Marca / Viviane de Medeiros Calaça Gomes; orientador: Luis Fernando Hor-Meyll Alvares. - 2012.

93f. : il. ; $30 \mathrm{~cm}$

Dissertação (mestrado) - Pontifícia Universidade Católica do Rio de Janeiro, Departamento de Administração, 2012.

Inclui bibliografia

1. Administração - Teses. 2. comunicação bocaa-boca. 3. avaliações online. 4. Comprometimento com a marca. I. Hor-Meyll, Luis Fernando. II. Pontifícia Universidade Católica do Rio de Janeiro. Departamento de Administração. III. Título.

CDD: 658 


\section{Agradecimentos}

À Deus, por me ajudar a concluir mais uma etapa importante em minha vida.

Ao meu marido Carlos, pelo grande apoio e incentivo para conclusão desta pesquisa, pela compreensão pela minha dedicação intensa ao Mestrado e especialmente, pela grande ajuda na configuração da loja virtual utilizada no experimento.

A minha mãe Sueli e meu irmão Marcus pelo apoio e compreensão por minha ausência, principalmente nos meses finais de elaboração deste trabalho.

Ao meu orientador, Luis Fernando Hor-Meyll, pelo incentivo na realização da minha pesquisa, pelo direcionamento e ajuda ao longo dos últimos meses.

Aos professores Jorge Brantes e Eduardo Ayrosa pela disponibilidade em participar desta banca e pelas contribuições para melhoria desta pesquisa.

Ao aluno de Pibic, Marco pela grande ajuda na aplicação dos questionários.

Aos funcionários da secretaria de graduação, Rita e Gabriel, por serem muito solícitos e pelo apoio na reserva do laboratório e impressão dos questionários.

A todos os alunos de graduação em Administração que colaboraram participando da pesquisa. 


\section{Resumo}

Gomes, Viviane de Medeiros Calaça; Alvares, Luis Fernando Hor-Meyll Influência de Avaliações Online Negativas na Atitude e na Intenção de CompraRio de Janeiro, 2012. 93p. Dissertação de Mestrado Departamento de Administração, Pontifícia Universidade Católica do Rio de Janeiro.

A comunicação boca-a-boca sempre desempenhou um importante papel no processo decisório do consumidor, como fonte de informação relevante e confiável. A Internet possibilitou que consumidores pudessem compartilhar suas avaliações sobre marcas, produtos e serviços com um incontável número de pessoas, dando origem à comunicação boca-a-boca eletrônica. Este estudo concentra-se na comunicação boca-a-boca que acontece nas lojas virtuais, onde os consumidores compartilham suas opiniões, positivas ou negativas, sobre os produtos comercializados no site. Com base no modelo Elaboration Likelihood Model, este trabalho avaliou o efeito da quantidade e da qualidade das avaliações negativas disponibilizadas nos sites de compras na atitude e na intenção de compra dos consumidores, utilizando o comprometimento com a marca como moderador deste efeito. Utilizando uma loja virtual para realização do experimento, onde foram disponibilizadas avaliações sobre a câmera digital Sony, foi possível verificar em quais condições avaliações negativas influenciam negativamente a atitude e intenção de compra. Os resultados obtidos ajudam a complementar as pesquisas já realizadas e ampliam a compreensão sobre o assunto.

\section{Palavras-chave}

Comunicação boca-a-boca online; Elaboration Likelihood Model; comunicação boca-a-boca negativa. 


\section{Abstract}

Gomes, Viviane de Medeiros Calaça; Alvares, Luis Fernando Hor-Meyll (Advisor). Impact of Negative Online Evaluations on Attitude and Buying Intention. Rio de Janeiro, 2012. 93p. MSc. Dissertation Departamento de Administração, Pontifícia Universidade Católica do Rio de Janeiro.

Word-of-mouth plays an important role as a communication channel during consumer decision processes, as a relevant and reliable source of information. Internet has allowed consumers to share online their opinions and evaluations with consumers all over the world. This study focused on word-of-mouth published on web stores, where consumers share their positive or negative opinions about products that are available at the store. Based on the Elaboration Likelihood Model, an experiment was carried out to evaluate effects of quantity and quality of negative online reviews on attitude and purchasing intention and the moderating effect of brand commitment. Results contribute to the knowledge about online consumer reviews and its influence on purchase behavior.

\section{Keywords}

Electronic word-of-mouth; Elaboration Likelihood Model; negative wordof-mouth. 


\section{Sumário}

1. Introdução 12

1.1. Objetivo do Estudo 14

1.2. Relevância do Estudo 14

1.3. Delimitação do Estudo 16

2. Revisão de Literatura $\quad 18$

2.1. A Comunicação Boca-A-Boca Eletrônica 18

2.2. Geração e Leitura das Avaliações Online 20

2.2.1. Motivações para Compartilhar Avaliações Online 20

2.2.2. Motivações para ler as Avaliações Online 22

2.3. Como as Avaliações são Processadas 24

2.3.1. O Modelo Elm 24

2.3.2. O Efeito da Negatividade e a Resistência a Persuasão 26

2.4. Influência da Comunicação Boca-A-Boca Eletrônica no
Comportamento do Consumidor

2.4.1. A Influência na Venda de Produtos Serviços 30

2.4.2. A Utilidade Percebida das Avaliações 31

2.4.3. A influência na Atitude e na Intenção de Compra 31

3. Hipóteses da Pesquisa

4. Método 38

4.1. Tipo de Pesquisa 38

4.1.1. Plano Fatorial 38

4.1.2. Identificação dos Possíveis Produtos 39

4.1.3. Escolha do Produto e da Marca 41

4.1.4. Criação da Loja Virtual 44

4.1.5. Variáveis Independentes 45

4.1.6. Variáveis Dependentes 48

4.1.7. Variáveis de Controle $\quad 49$

4.1.8. Realização do Experimento $\quad 50$

4.1.9. Limitações do Método 51

5. Análise dos Dados 52

5.1. Manipulação das Variáveis Independentes 53

5.2. Comprometimento com a Marca x Envolvimento 55

5.3. Mudança na Atitude 56

5.4. Influência da Quantidade e Qualidade de Avaliações Online

5.4.1. Grupo com Baixo Envolvimento 58

5.4.2. Grupo com Alto Envolvimento 63 
6. Considerações Finais 68

6.1. Conclusões 68

6.2. Aplicações Práticas $\quad 70$

6.3. Sugestões para Pesquisas Futuras 71

7. Referências Bibliográficas $\quad 72$

8. Anexos 76

8.1. Anexo I - Questionário para Escolha do Produto 76

8.2. Anexo II - Questionário para Escolha da Marca 77

8.2.1. Câmera Digital da Sony $\quad 77$

8.2.2. Telefone Celular Nokia $\quad 79$

8.2.3. Notebook da Samsung 81

8.3. Anexo III - resultados do Questionário para Escolha da Marca 83

8.3.1. Câmera Digital da Sony 83

8.3.2. Telefone Celular da Nokia 83

8.3.3. Notebook Samsung 84

8.4. Anexo IV - Objetivo e Instruções para o Experimento 85

8.5. Anexo V - Questionário Final 86

8.6. Anexo VI - imagens da Loja Virtual 90 


\section{Lista de figuras}

Figura 1 - Confiança do Consumidor em Diferentes Fontes de Informação

Figura 2 - Evolução das Pesquisas Sobre Comunicação Boca-aBoca Eletrônica

Figura 3 - Grupos para o Experimento 39

Figura 4 - Resultados do Questionário para Escolha do Produto 41

Figura 5 - Loja Virtual Criada para o Experimento 44

Figura 6 - Efeito da Quantidade e Qualidade de Avaliações Online Negativas na Atitude - Alunos com Baixo Comprometimento

Figura 7 - Efeito da Quantidade e Qualidade de Avaliações Online Negativas na Intenção de Compra - Alunos com Baixo

Comprometimento

Figura 8 - Efeito da Quantidade e Qualidade de Avaliações Online Negativas na Atitude - Alunos com Alto Comprometimento

Figura 9 - Efeito da Quantidade e Qualidade de Avaliações Online Negativas na Intenção de Compra - Alunos com Alto

Comprometimento

Figura 10 - Foto da Câmera Digital

90

Figura 11 - Descrição da Câmera Digital

90

Figura 12 - Especificações da Câmera Digital 91

Figura 13 - Avaliações dos Clientes - Site 1

Figura 14 - Avaliações dos Clientes - Site $2 \quad 92$

Figura 15 - Avaliações dos Clientes - Site $3 \quad 92$

Figura 16 - Avaliações dos Clientes - Site 4 


\section{Lista de tabelas}

Tabela 1 - Principais marcas dos produtos pré-selecionados 42

Tabela 2 - Marcas pré-selecionadas para cada produto 42

Tabela 3 - Estatística Descritiva - Câmera Digital da Sony 43

Tabela 4 - Avaliações negativas utilizadas no experimento 46

Tabela 5 - Avaliações positivas utilizadas no experimento 47

Tabela 6 - Distribuição da amostra nas diferentes condições 52

Tabela 7 - Estatísticas Descritivas da Percepção de Proporção de Avaliações Negativas

Tabela 8 - Estatísticas Descritivas da Percepção da Qualidade das Avaliações

Tabela 9 - Estatísticas Descritivas da Atitude Inicial, Atitude Final e Variação da Atitude

Tabela 10 - Estatísticas Descritivas da Atitude de Consumidores com Baixo Comprometimento

Tabela 11 - Estatísticas Descritivas da Intenção de Compra de Consumidores com Baixo Comprometimento

Tabela 12 - Estatísticas Descritivas da Atitude de Consumidores com Alto Comprometimento

Tabela 13 - Estatísticas Descritivas da Intenção de Compra de Consumidores com Alto Comprometimento 